\title{
Modulation of the Rat Hepatic Cytochrome P4501A Subfamily Using Biotin Supplementation
}

\author{
M. D. Ronquillo-Sánchez, R. Camacho-Carranza, C. Fernandez-Mejia, S. Hernández-Ojeda, \\ M. Elinos-Baez, and J. J. Espinosa-Aguirre
}

Instituto de Investigaciones Biomédicas, Universidad Nacional Autónoma de México, Apdo. Postal 70228, 04510 México, DF, Mexico

Correspondence should be addressed to J. J. Espinosa-Aguirre; jjea99@gmail.com

Received 14 April 2013; Accepted 2 July 2013

Academic Editor: Anastasia Kotanidou

Copyright ( 2013 M. D. Ronquillo-Sánchez et al. This is an open access article distributed under the Creative Commons Attribution License, which permits unrestricted use, distribution, and reproduction in any medium, provided the original work is properly cited.

\begin{abstract}
Studies have found that biotin favors glucose and lipid metabolism, and medications containing biotin have been developed. Despite the use of biotin as a pharmacological agent, few studies have addressed toxicity aspects including the possible interaction with cytochrome P450 enzyme family. This study analyzed the effects of pharmacological doses of biotin on the expression and activity of the cytochrome P4501A subfamily involved in the metabolism of xenobiotics. Wistar rats were treated daily with biotin $(2 \mathrm{mg} / \mathrm{kg}$, i.p.), while the control groups were treated with saline. All of the rats were sacrificed by cervical dislocation after 1, 3, 5, or 7 days of treatment. CYP1A1 and CYP1A2 mRNAs were modified by biotin while enzyme activity and protein concentration were not affected. The lack of an effect of biotin on CYP1A activity was confirmed using other experimental strategies, including (i) cotreatment of the animals with biotin and a known CYP1A inducer; (ii) the addition of biotin to the reaction mixtures for the measurement of CYP1A1 and CYP1A2 activities; and (iii) the use of an S9 mixture that was prepared from control and biotin-treated rats to analyze the activation of benzo[a]pyrene $(\mathrm{BaP})$ into mutagenic metabolites using the Ames test. The results suggest that biotin does not influence the CYP1A-mediated metabolism of xenobiotics.
\end{abstract}

\section{Introduction}

The vitamin biotin acts as a covalently bound coenzyme of carboxylases. Unrelated to this role, biotin supplementation modifies gene expression [1-5] and displays a wide repertoire of effects on systemic processes [6]. DNA microarray studies and high-throughput immunoblotting studies have aided in the identification of thousands of genes whose expression levels are modified by biotin at both the transcriptional and the posttranscriptional levels [5,7]. Biotin supplementation modifies the expression of critical genes that are involved in the regulation of carbohydrate and lipid metabolism [8-14]. In agreement with these findings, several observations have indicated that biotin supplementation improves glucose and triglyceride homeostasis [15-19], which has led to the development of commercially available medications containing pharmacologically relevant amounts of biotin $(2 \mathrm{mg} /$ day $)$ in combination with chromium picolinate $[20,21]$.
Despite its use as a pharmacological agent, few studies have addressed the toxicity of biotin [22-25]. DNA microarray studies have provided evidence that biotin supplementation increases the levels of mRNA encoding cytochrome $\mathrm{P} 450$ (CYP)1B1 in human peripheral blood mononuclear cells in vitro [5]. In addition, the transcriptional activation of this gene was associated with the increased activity of CYP1B1 in human lymphoid cells and with the increased frequency of single-stranded DNA breaks [26].

CYP enzymes are a superfamily of hemoproteins that metabolize endogenous compounds and foreign substances (xenobiotics) in several organisms, including mammals [27]. The CYP1 family members are particularly important due to their capacity to "activate" a broad variety of procarcinogens and some drugs, leading to the formation of highly reactive metabolites that can react with macromolecules, including proteins, lipids, and nucleic acids [28, 29]. Additionally, CYP expression is further subject to chemical induction or inhibition that results in quantitative variations in 
metabolic activity. The modulation of CYP expression is implicated in at least two scenarios: (i) drug-drug interactions, leading to adverse health effects and (ii) inhibition of mutagenic/carcinogenic compound metabolism, leading to antimutagenic/anticarcinogenic effects. Therefore, the evaluation of the capacity of any new compound that is intended for human use to interact with the CYP enzymes that are involved in xenobiotic metabolism is mandatory.

Although biotin consumption is considered to be safe [22], studies evaluating its toxicity at high doses need to be carefully conducted, as biotin supplementation affects gene expression and physiological functions. In this study, we analyzed the effects of pharmacological doses of biotin on the expression and activity of members of the CYP1A subfamily that are involved in the metabolism of procarcinogens and some drugs.

\section{Materials and Methods}

2.1. Chemicals. Biotin, ethoxyresorufin (ER), methoxyresorufin (MR), resorufin, dimethyl sulfoxide (DMSO), benzo[a]pyrene $(\mathrm{BaP})$, and NADPH were purchased from Sigma Chemical Co. (St. Louis, MO, USA). Rabbit polyclonal anti-rat CYP1A1 and rabbit polyclonal anti-rat CYP1A2 were both purchased from Chemicon International Inc. (Atlanta, GA, USA), Mouse polyclonal anti-rat GAPDH was obtained from Millipore (Billerica, MA, USA). Rabbit anti-mouse peroxidase and goat anti-rabbit peroxidase were obtained from Invitrogen Life Technologies (CA, USA). The chemicals that were used for electrophoresis and the nitrocellulose membranes were purchased from Bio-Rad Laboratories (Richmond, CA, USA). Trizol reagent, M-MLV reverse transcriptase, and oligo dT primers were purchased from Invitrogen Life Technologies (CA, USA). Taq Man universal PCR master mix, unlabeled PCR primers, and TaqMan MGB probes were purchased from Applied Biosystems (Foster City, CA, USA).

2.2. Animals. This study was approved by the Ethical Committee for Experimentation of the Biomedical Research Institute of the National Autonomous University of Mexico. Male Wistar rats (200-250 g body weight) were obtained from the animal facility at the Biomedical Research Institute of the National Autonomous University of Mexico and were handled according to the standard procedures that were established by the Ethical Committee for Experimentation at the same institute. Animals were maintained under a 12/12hr light/dark cycle and were allowed to consume water and food ad libitum throughout the experimental periods, with the exception of the fasting period prior to sacrifice.

\subsection{In Vivo Studies}

2.3.1. Animals Treated with Biotin. Thirty-two rats were divided into eight groups: four control groups and four experimental groups (each group contained four animals). The control groups were treated daily with saline (phosphatebuffered, i.p.), and the experimental groups were treated daily with biotin ( $2 \mathrm{mg} / \mathrm{kg}$, i.p.) at doses that were equivalent to pharmacological doses of biotin. All of the rats were sacrificed by cervical dislocation after $1,3,5$, or 7 days of treatment.

2.3.2. Animals Treated with Biotin and Benzo[a]pyrene. We examined the effects of treatment with biotin in combination with $\mathrm{BaP}$, a well-known CYP inducer, to examine the possible additive effects of these agents. Twenty rats were divided into four groups (five animals per group): control (saline), biotin treated ( $2 \mathrm{mg} / \mathrm{kg}$, i.p.), BaP treated $(15 \mathrm{mg} / \mathrm{kg}$, i.p.), and biotin $+\mathrm{BaP}$ treated $(2 \mathrm{mg} / \mathrm{kg}$ of biotin and $15 \mathrm{mg} / \mathrm{kg}$ of $\mathrm{BaP})$. All of the rats were sacrificed by cervical dislocation after $24 \mathrm{hrs}$ of treatment. Liver microsomes were prepared to measure the ethoxyresorufin O-deethylase (EROD) and methoxyresorufin $O$-demethylase (MROD) activities.

\subsubsection{Preparation of the Liver S9 and Microsomal Fractions of} Treated Animals. Liver S9 fractions were prepared according to the procedure described by Maron and Ames [30]. The rats were sacrificed by cervical dislocation, after which point their livers were rapidly removed, weighed, and washed in a $0.15 \mathrm{M} \mathrm{KCl}$ solution and minced. Each sample was separately homogenized in the same solution $(3 \mathrm{~mL} / \mathrm{g}$ liver). The homogenates were centrifuged at $9,000 \times \mathrm{g}$ for $10 \mathrm{~min}$, and the supernatants were stored at $-80^{\circ} \mathrm{C}$. A portion of this supernatant fraction was centrifuged at $105,000 \times \mathrm{g}$ for $60 \mathrm{~min}$ aseptically at $4^{\circ} \mathrm{C}$. The microsomal pellet was resuspended in a phosphate-buffered solution $\left(67.5 \mathrm{mM} \mathrm{K}_{2} \mathrm{HPO}_{4}\right.$ and $32.5 \mathrm{mM} \mathrm{KH}_{2} \mathrm{PO}_{4}, \mathrm{pH}=7.4$ ) and centrifuged again. Finally, the microsomes were stored in the same phosphate-buffered solution containing $1 \mathrm{mM}$ dithiothreitol, $1 \mathrm{mM}$ EDTA, and $20 \%$ glycerol, aliquoted into a series of labeled vials, and frozen at $-80^{\circ} \mathrm{C}$. The protein content of each sample was determined using the method outlined by Bradford [31].

2.3.4. RNA Isolation and Quantitative Real-Time RT-PCR Expression Analysis of the Cytochrome P450 Enzymes. Total RNA was extracted from frozen liver tissues using Trizol reagent (Invitrogen Life Technologies, CA, USA). The RNA concentration was determined by measuring the optical density at $260 \mathrm{~nm}$, and the purity was determined by calculating the $\mathrm{OD}_{260} / \mathrm{OD}_{280}$ absorption ratio (all ratios were ensured to be $>1.8$ ). RNA integrity was confirmed by electrophoresis on a $1 \%$ denaturing agarose gel. The chemicals that were used for reverse transcription were purchased from Invitrogen Life Technologies (CA, USA). The isolated RNA was reversetranscribed using Moloney murine leukemia virus reverse transcriptase (M-MLV RT). Briefly, the RNA was denatured by heating it at $65^{\circ}$ for $5 \mathrm{~min}$, cooled on ice, and incubated in a reverse transcriptase reaction mixture. The standard mixture contained $1 \mu \mathrm{g}$ of total RNA, 40 units/ $\mu \mathrm{L}$ of RNaseOUT recombinant ribonuclease inhibitor, $10 \mathrm{mM}$ concentrations of each of the dNTPs, $1 \mu \mathrm{L}$ of oligo $(\mathrm{dT})_{12-18}, 4 \mu \mathrm{L}$ of $5 \mathrm{X}$ first-strand buffer, $2 \mu \mathrm{L}$ of $0.1 \mathrm{M}$ DTT, and $200 \mathrm{U}$ of M-MLV reverse transcriptase in a total volume of $20 \mu \mathrm{L}$. For reverse transcription, the tubes were incubated at $37^{\circ}$ for $50 \mathrm{~min}$, followed by rapid cooling. 
PCR was performed using an ABI PRISM 7500 sequence detection system (Applied Biosystems (Foster City, CA, USA) using melting, annealing, and extension cycling conditions of $95^{\circ}$ for $15 \mathrm{sec}, 50^{\circ}$ for $2 \mathrm{~min}$, and $60^{\circ}$ for $1 \mathrm{~min}$. All amplifications were repeated for 40 cycles. Taq-Man Gene expression primers (Applied Biosystems, Foster City, CA, USA) were used to detect CYP1A1 (Rn 00487218_m1), CYP1A2 (Rn 00561082_m1), and GAPDH (Rn 99999916_s1). The quantitative expression levels of the genes were calculated based on the cycle threshold (CT) value of each sample at the linear part of the curve using the $2^{-\Delta \Delta C T}$ relative quantification method [32]. All of the samples were assayed in triplicate. The values for each gene were normalized to the value of the housekeeping gene, GAPDH.

2.3.5. Quantitative Real-Time RT-PCR Analyses of miR-27b, $m i R-122$, and miR-328a Expression. To evaluate the concentrations of miR-27b, miR-122, and miR-328a, we performed quantitative real-time reverse transcription PCR assays in rat liver samples. The total RNA and miRNA fractions were isolated from the livers of control and biotin-supplemented rats using a small RNA isolation kit (Ambion, CA, USA). The miRNA expression levels were quantified using the mirVana qRT-PCR miRNA detection protocol (Ambion, CA, USA). The primers used were obtained from Applied Biosystems (Foster City, CA, USA) to detect miR-27b (rno-miR-27b* 464436_mat), miR-122 (rno-mir-122* 463893-mat), and miR328a (rno-mir-328a* 462041-mat). Mature miRNA U87 was used as internal reference to normalize the RNA levels of the genes being studied. Each PCR reaction was performed in triplicate in a $20 \mu \mathrm{L}$ volume using TaqMan MicroRNA assays (Applied Biosystems) for $10 \mathrm{~min}$ at $95^{\circ} \mathrm{C}$, followed by 40 cycles at $95^{\circ} \mathrm{C}$ for $15 \mathrm{~s}$ and $60^{\circ} \mathrm{C}$ for $60 \mathrm{~s}$ in an ABI PRISM 7500 Sequence Detection System (Applied Biosystems). The miRNA levels were quantified using the $2^{-\Delta \Delta C T}$ relative quantification method [32] using the following formula: 2(CTmicroRNA-CTU87).

2.3.6. CYP1A1 and CYP1A2 Activities. The formation of resorufin after $O$-dealkylation of 7-ethoxyresorufin and 7methoxyresorufin, which are metabolic probes for the activity of CYP1A1 and CYP1A2, respectively, was measured spectrofluorometrically according to the procedure outlined by Burke et al. [33]. The catalytic activities were calculated from a standard curve of resorufin $(5-500 \mathrm{pmol} / \mathrm{mL})$. The excitation and emission wavelengths were set at 530 and $590 \mathrm{~nm}$, respectively.

2.3.7. Western Blot Analyses. Hepatic microsomes were used for the determination of CYP activity. Ten micrograms of the microsomal proteins from individual animals were separated using 7.5\% SDS-PAGE and were transferred to $0.45 \mathrm{~mm}$ nitrocellulose sheets overnight [34]. The nitrocellulose membranes were blocked for $1 \mathrm{hr}$ with $5 \%$ nonfat dry milk in phosphate-buffered saline at $4^{\circ} \mathrm{C}$ [35]. After a $10 \mathrm{~min}$ wash with PBS containing $0.3 \%$ Tween-20, the membranes were incubated with the corresponding anti-rat primary antibodies, anti-CYP1A1 (1:10000), and anti-CYP1A2 (1:10000), at room temperature for $1 \mathrm{hr}$. The membranes were then incubated with horseradish peroxidase-conjugated anti-rabbit or anti-mouse IgG secondary antibodies at room temperature for $1 \mathrm{hr}(1: 6400)$. To confirm equal loading in each lane, the protein levels of the CYP enzymes were normalized to the GAPDH protein levels. The proteins of interest were revealed using Luminol. Relative increases in band intensity over the controls for each CYP isoform were determined using 1D Kodak 3.6.3 v computer software.

\subsection{In Vitro Studies}

2.4.1. Biotin-CYP Interactions. We determined both the EROD and MROD activities in the microsomes of rats that had been treated with phenobarbital $(60 \mathrm{mg} / \mathrm{kg}$, i.p., for the first three days and $30 \mathrm{mg} / \mathrm{kg}$, i.p., on day four) and $\beta$ naphthoflavone $(80 \mathrm{mg} / \mathrm{kg}$, i.p., on day three) in the presence or absence of different concentrations of biotin to explore whether this vitamin could interfere with these enzyme activities. Buffer (50 mM Tris- $\mathrm{HCl}$ and $25 \mathrm{mM} \mathrm{MgCl}_{2}, \mathrm{pH}=$ 7.6), the substrate (dissolved in DMSO), and NADPH were incubated at $37^{\circ} \mathrm{C}$ for $3 \mathrm{~min}$ in a fluorometry cuvette. The enzymatic reactions were initiated by adding total microsomal proteins $(200 \mu \mathrm{g})$ at the same time that we added different concentrations of biotin $(1,2.5,5$, and $10 \mu \mathrm{g} / \mathrm{mL})$. The reactions were followed for $3 \mathrm{~min}$, and the fluorescence was recorded every $15 \mathrm{~s}$. The catalytic activities were calculated from a standard curve of resorufin $(5-500 \mathrm{pmol} / \mathrm{mL})$. The excitation and emission wavelengths were set at 530 and $590 \mathrm{~nm}$, respectively.

2.4.2. Ames Test. The Salmonella mutagenicity plate incorporation test was performed according to the method described by Maron and Ames [30]. Bacterial cultures were obtained by the inoculation of a liquid nutrient broth with the $S$. typhimurium strain TA98 and were incubated at $37^{\circ} \mathrm{C}$ with shaking overnight. We examined the liver S9 fractions from both control rats and rats that had been treated with biotin ( $2 \mathrm{mg} / \mathrm{kg}$, i.p.) for $1,3,5$, and 7 days. The $\mathrm{S} 9$ mixture consisted of the S9 fraction $(0.1 \mathrm{~mL} / \mathrm{mL}$ of $\mathrm{S} 9), \mathrm{MgCl}_{2}(8 \mathrm{mM}), \mathrm{KCl}$ (33 mM), glucose 6-phosphate $(5 \mathrm{mM})$, and $\mathrm{NADP}^{+}(4 \mathrm{mM})$ in $50 \mathrm{mM}$ phosphate buffer $(\mathrm{pH}=7.4)$. The bacterial cultures $(0.1 \mathrm{~mL}), \mathrm{BaP}(1,5,10$, and $20 \mu \mathrm{g}$ per plate $)$, and the $\mathrm{S} 9$ mixture $(0.5 \mathrm{~mL})$ were mixed with soft agar and poured onto Petri dishes containing Vogel-Bonner minimal medium. The plates were incubated for 48-72 hrs, and the numbers of revertant colonies $\left(\mathrm{His}^{+}\right.$) were recorded.

2.5. Statistical Analyses. All statistical analyses were performed using commercially available GraphPad Prism v 4.0 (La Jolla, CA, USA) software. The data were expressed as the means \pm SEM. Statistical significance was assessed using Student's $t$-test, with the levels of significance set at $P \leq 0.05$. 


\section{Results}

3.1. Effects of Biotin on P450 mRNA Levels. To evaluate whether pharmacological concentrations of biotin can modulate CYP1A expression in in vivo studies, we examined mRNA levels in the livers of rats that had been treated with biotin $(2 \mathrm{mg} / \mathrm{kg})$ at different times after administration. The results demonstrated that biotin significantly increased CYP1A1 and CYP1A2 mRNA levels (by $2.23 \pm 0.22$ and $1.50 \pm 0.10$ folds, resp.) after 24 hrs of biotin treatment, as shown in Figures 1(a) and 2(a). It is interesting to note that the increase in CYP1A1 decreased after 3 days $(0.24 \pm 0.01$ fold decrease $)$ compared with the control. At 5 and 7 days after biotin treatment, CYP1A1 and CP1A2 began to return to control levels.

3.2. Analysis of CYP Protein Expression. CYP protein expression in the rat livers was evaluated using Western blot (Figures 1(b) and 2(b)). Densitometric analyses of the bands revealed that the protein concentrations were not affected by biotin treatment on different days $(P \leq 0.05)$.

3.3. Effects of Biotin on CYP Activities. The levels of CYP1A1 and CYP1A2 activities were slightly higher than those in the controls at day 1 , but the differences were not statistically significant $(P \leq 0.05)$. No changes were noted after 3,5 , and 7 days of biotin treatment (Figures 1(a) and 2(a)). These results corresponded to the effects that were observed at the protein level. The same microsomal samples that were used for the immunoblots were used for the enzymatic activity determinations.

3.4. Effects of Biotin on BaP-Induced CYP Activity. Biotin was administered to rats in combination with $\mathrm{BaP}$, a typical inducer of members of the CYP1A subfamily, to analyze whether the vitamin potentiated the capacity of $\mathrm{BaP}$ to increase CYP1A activity. The hepatic microsomal EROD and MROD activities were similar in animals that had been treated with either $\mathrm{BaP}$ alone or both biotin and $\mathrm{BaP}$ (Figure 3).

3.5. Determination of the Possible Interactions between Biotin and the Catalytic Activities of CYP1A1 and CYP1A2. To investigate whether biotin could interfere with the EROD and MROD activities, we used phenobarbital/ $\beta$-naphthoflavoneinduced rat liver microsomes. Different concentrations of biotin were added to the reaction mixtures with ER or MR. Biotin did not interfere with the activities of the CYP enzymes studied (Figure 4).

3.6. Ames Test. The mutagenic potencies of $\mathrm{BaP}$ resulting from its activation by S9 mixtures that were prepared from either the livers of biotin-treated rats or those prepared from the livers of control animals were very similar (Table 1). BaP had a mutagenic potency of $57.2 \mathrm{rev} / \mu \mathrm{g}$ when activated by $\mathrm{S} 9$ mixtures that had been prepared from the livers of rats after $24 \mathrm{hrs}$ of biotin treatment and a potency of $40.5 \mathrm{rev} / \mu \mathrm{g}$ when activated by $S 9$ mixtures that had been prepared from the livers of control rats. The mutagenic potencies of $\mathrm{BaP}$ that had

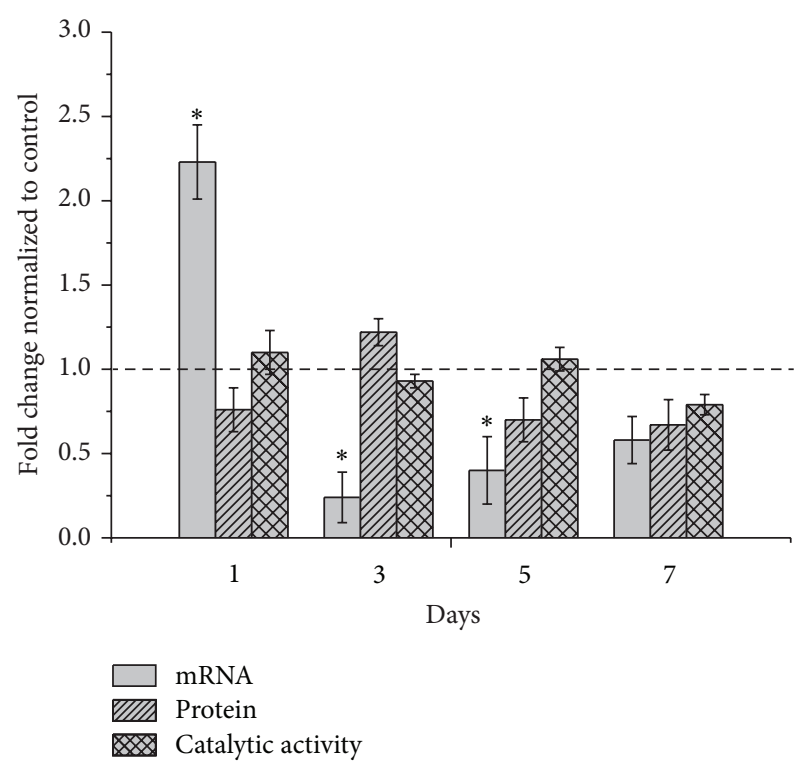

(a)

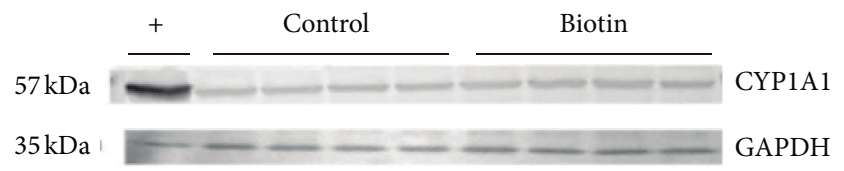

(b)

FIGURE 1: Relative CYP1A1 mRNA, protein, and catalytic activity levels after $1,3,5$, and 7 days of biotin treatment $(2 \mathrm{mg} / \mathrm{kg}$, i.p.). The data are expressed as fold changes relative to the control group (dashed line). The data represent the means \pm SEM of 4 rats per group from two independent experiments. * Significantly different from the controls $(P \leq 0.05)$, as assessed using Student's $t$-test (a). Representative CYP1A1 immunoblot ( $24 \mathrm{hrs}$ after biotin treatment). The intensities of the bands were normalized to GAPDH. The values are expressed as fold changes relative to the control group (dashed line). The $(+)$ band corresponds to liver microsomes that were prepared from rats that had been treated with $\mathrm{BaP}(10 \mathrm{mg} / \mathrm{kg})$, bands 2-5 are from control rats, and bands 6-9 correspond to biotintreated rats $(2 \mathrm{mg} / \mathrm{kg})$. The molecular weights of the bands are indicated on the left: $57 \mathrm{kDa}$ for CYP1A1 and $35 \mathrm{kDa}$ for GAPDH. Four animals were used per group, and the data represent the results of two independent experiments (b).

been activated by hepatic S9 from rats that had been treated with biotin for 7 days and S9 that had been prepared from the control animals were 15.0 and $16.5 \mathrm{rev} / \mu \mathrm{g}$, respectively. In contrast, the mutagenic potencies of $\mathrm{BaP}$ that had been activated by $\mathrm{S} 9$ mixtures that had been prepared from rats that had been pretreated with a combination of known CYP inducers ranged from 37.4 to $62.3 \mathrm{rev} / \mu \mathrm{g}$.

3.7. Expression of miRNAs. We also evaluated the levels of miR-27b, miR-122, and miR-328a in rat liver at different times after biotin treatment $(2 \mathrm{mg} / \mathrm{kg})$. The expression levels of the three miRNAs studied were increased after $24 \mathrm{hrs}$ of biotin treatment. The levels of $\mathrm{miR}-27 \mathrm{~b}$ remained increased after 3 and 5 days of biotin treatment, and the levels of the three 


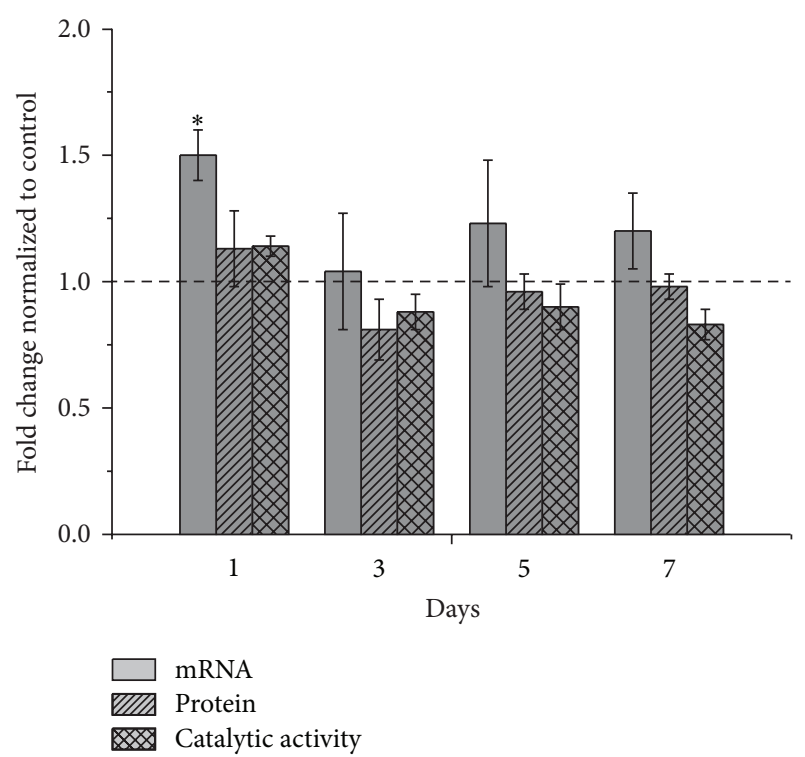

(a)

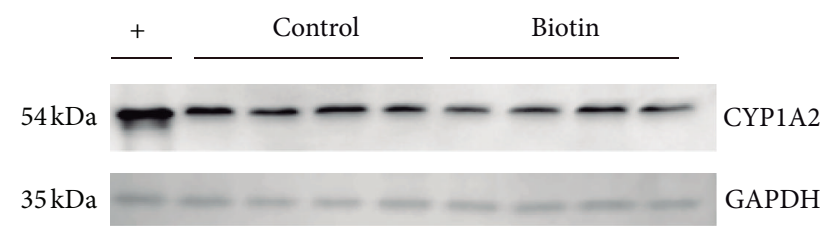

(b)

FIGURE 2: Relative CYP1A2 mRNA, protein, and catalytic activity levels after $1,3,5$, and 7 days of biotin treatment $(2 \mathrm{mg} / \mathrm{kg}$, i.p.). The data are expressed as fold changes relative to the control group (dashed line). The data represent the means \pm SEM of 4 rats per group from two independent experiments. *Significantly different from the controls $(P \leq 0.05)$, as assessed using Student's $t$-test (a). Representative CYP1A2 immunoblot ( $24 \mathrm{hrs}$ after biotin treatment). The intensities of the bands were normalized to GAPDH. The values are expressed as fold changes relative to the control group (dashed line). The $(+)$ band corresponds to liver microsomes that were prepared from rats that had been treated with $\mathrm{BaP}(10 \mathrm{mg} / \mathrm{kg})$, bands 2-5 are from control rats, and bands 6-9 correspond to biotintreated rats $(2 \mathrm{mg} / \mathrm{kg})$. The molecular weights are indicated on the left: $54 \mathrm{kDa}$ for CYP1A2 and $35 \mathrm{kDa}$ for GAPDH. Four animals were used per group, and the data represent the results of two independent experiments (b).

miRNAs that were studied had returned to control levels after 7 days of treatment (Figure 5).

\section{Discussion}

Few studies have evaluated the toxicity of biotin [22-25]. Furthermore, studies that evaluated the toxicity of concentrations above normal levels need to be carefully readdressed given that the number of commercially available supplements that contain pharmacological amounts of the vitamin has increased [20]. In this work, we analyzed the effects of i.p. doses of $2 \mathrm{mg} / \mathrm{kg}$ of biotin on the expression and activity of members of the CYP1A subfamily that are involved in drug

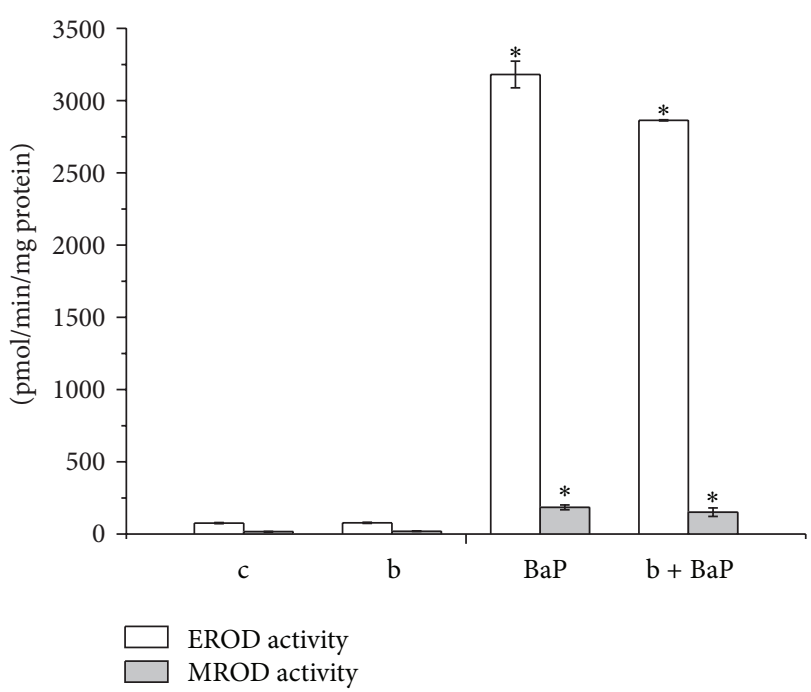

FIGURE 3: Effects of biotin treatment on EROD and MROD levels in the hepatic tissues of rats that were treated with a single i.p. dose of PBS 1X (control), biotin $(2 \mathrm{mg} / \mathrm{kg}), \mathrm{BaP}(10 \mathrm{mg} / \mathrm{kg})$, or biotin + $\mathrm{BaP}(2 \mathrm{mg} / \mathrm{kg}$ of biotin plus $10 \mathrm{mg} / \mathrm{kg}$ of $\mathrm{BaP})$. EROD activity: (pmol of resorufin formed/min/mg of protein); MROD activity: (pmol of resorufin formed $/ \mathrm{min} / \mathrm{mg}$ of protein). The results represent the means \pm SEM. $n=5$ rats per group. A $P \leq 0.05$ was considered to be significantly different from the control group using Student's $t$-test.

and xenobiotic metabolism. This dose of biotin is known to induce the expression of genes that are related to glucose metabolism [36].

Our results revealed that biotin administration modified CYP1A expression but did not alter the activity or protein concentrations of CYP1A (Figures 1 and 2). The finding that biotin administration did not affect CYP1A2 activity is of clinical interest because this enzyme is involved in the metabolism of numerous drugs, including clozapine, theophylline, tacrine, and verapamil, among others [37]. Therefore, alterations of the basal activity of CYP1A2 may cause clinically important drug-drug and food-drug interactions $[38,39]$. These findings suggest that there is a low probability of drug-drug interactions resulting from the coadministration of biotin with drugs that are metabolized by CYP1A2. Additionally, CYP1A1 metabolizes polycyclic aromatic hydrocarbons (PAHs), which are ubiquitous compounds that are found in petroleum and emissions that are produced during the combustion of fossil fuels, in charred meat and fish that have been cooked directly over a fire, in tobacco smoke, and in several other products that are the result of the incomplete combustion of organic matter [40]. The metabolites that are formed from the interaction of CYP1A1 and PAHs are well known to generate DNA adducts leading to mutagenic events and chromosome aberrations that can contribute to the carcinogenic process [41]. Therefore, the lack of effect of biotin on CYP1A1 activity that was observed in this work supports the idea that exposure to biotin at pharmacologically relevant concentrations is harmless. 


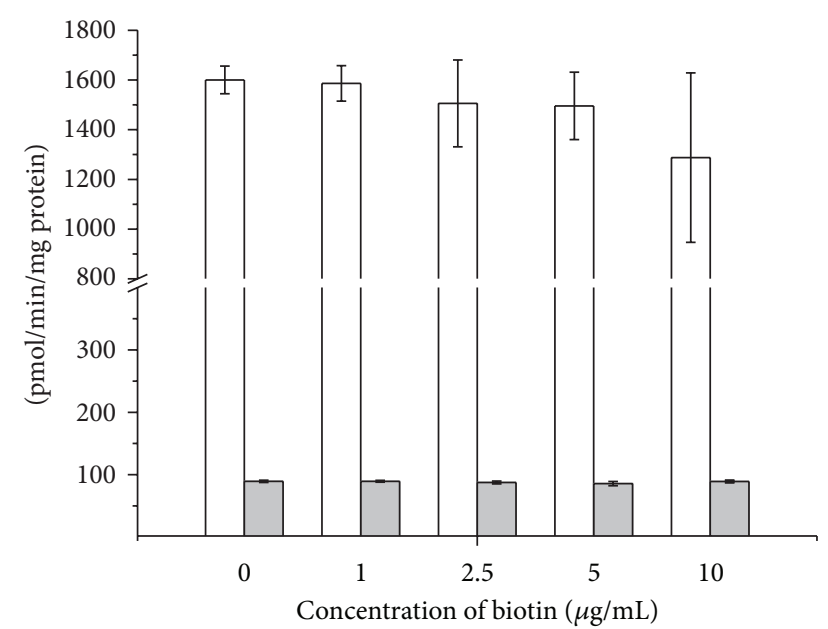

EROD activity

MROD activity

FIGURE 4: Effects of biotin treatment on EROD and MROD levels in the hepatic tissues of rats that were simultaneously treated with phenobarbital $(60 \mathrm{mg} / \mathrm{kg})$ and $\beta$-naphthoflavone $(80 \mathrm{mg} / \mathrm{kg})$. Increasing biotin concentrations were added to the reaction mixtures when measuring the enzymatic activity: (pmol of resorufin formed $/ \mathrm{min} / \mathrm{mg}$ of protein). The results represent the means \pm SEM of two independent experiments that were conducted in triplicate. A $P \leq 0.05$ was considered to be significantly different from the control group using Student's $t$-test.

To further investigate the possible role of biotin in the modulation of members of the CYP1A subfamily, we explored the effects of biotin administration along with the known CYP inducer BaP, a typical substrate and inducer of these enzymes. No differences were detected in the activities of either CYP1A1 or CYP1A2 in hepatic microsomes that were obtained from rats that had been treated with the combination of biotin $+\mathrm{BaP}$ or $\mathrm{BaP}$ alone (Figure 3). Furthermore, biotin did not interfere with the activities of CYP1A1 or CYP1A2 when it was added to the reaction mixtures containing ER as a CYP1A1 substrate or MR as a CYP1A2 substrate, indicating that biotin does not act as an inhibitor for members of the CYP1A subfamily (Figure 4).

Additional evidence supporting the notion that biotin does not modulate the activity of the CYP enzymes studied was obtained using the Ames test [30]. This assay has been used to estimate the biological significance of CYP modulation, as the production of mutagenic metabolites from a known promutagen is dependent upon the CYP activity in the $S 9$ mixture [42]. The $S 9$ mixture that was prepared from rat livers that had been treated with biotin activated $\mathrm{BaP}$ at similar levels to that of the $S 9$ mixture that had been prepared from the livers of control rats (Table 1). This result indicated that exposure to biotin did not alter the capacity of CYP1A1 to metabolize other substrates. Therefore, biotin may not influence CYP1A-mediated metabolism, further supporting its use as a therapeutic drug.

In contrast to the observed mRNA upregulation, CYP1A expression and enzyme activity were not significantly
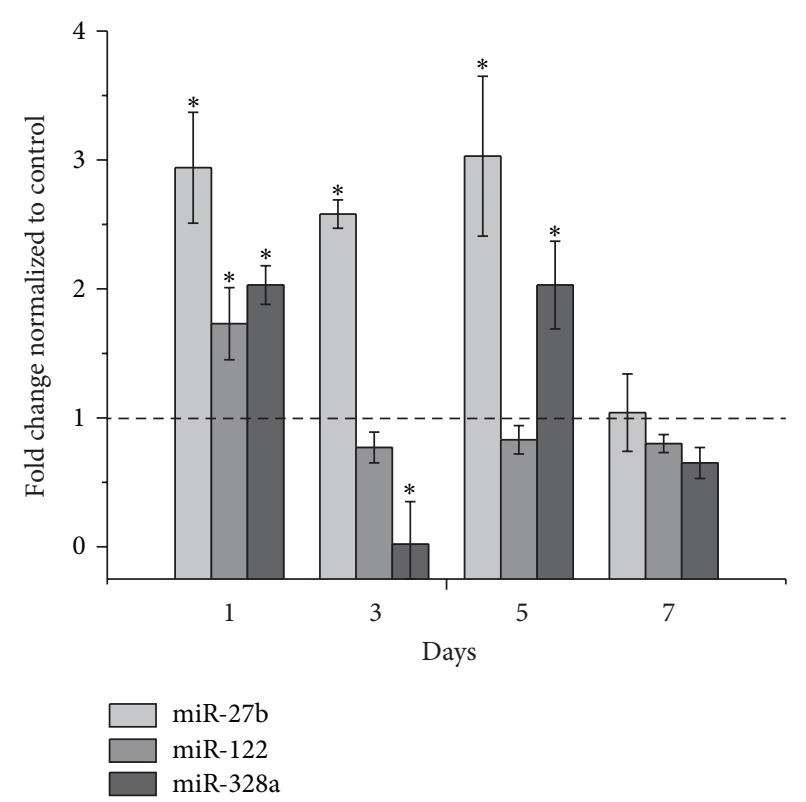

FIGURE 5: miR-27b, miR-122, and miR-328a levels after 1, 3, 5, and 7 days of biotin treatment $(2 \mathrm{mg} / \mathrm{kg}$, i.p. $)$ in rat liver. The data are expressed as fold changes relative to the control (defined as 1, dashed line). The data represent the means \pm SEM of 4 rats per group from two independent experiments. * Significantly different from the controls $(P \leq 0.05)$, as assessed using Student's $t$-test.

affected. These discrepancies may be explained by the fact that several studies have found that the abundance of selected proteins was not paralleled by the abundance of their mRNAs $[7,43]$. In addition, pyruvate carboxylase apoenzyme expression is regulated by biotin at the posttranscriptional level, thereby influencing both protein synthesis and degradation [44]. Taken together, our observations suggest that biotinbased posttranscriptional effects may also influence CYP1A expression.

One possible explanation for our results could be posttranscriptional regulation that is mediated by the presence of miRNAs, which are small noncoding RNAs that regulate transcriptional and posttranscriptional gene expression [45]. In this process, not all of the mRNAs are translated immediately. Some of the mRNAs are maintained in a translationally repressed state and may be transported to a specific cytoplasmic location where translation is activated [46]. Recent studies have provided evidence that mRNAs that are silenced by miRNAs are localized in P-bodies for storage or degradation [47]. miR-27b, miR-122, and miR328a have been recently reported to be associated with the regulation of CYP enzymes [48-50]. Using in silico tools, such as BLAST and miRBASE, we identified target sequences for these miRNAs in the CYP1A subfamily. Our results (Figure 5) support the idea that the upregulation of these miRNAs by biotin could be implicated in the posttranscriptional regulation of CYP1A, although we cannot rule out that other posttranscriptional mechanisms may participate, given that biotin influences both protein synthesis and degradation [44]. Therefore, we 
TABLE 1: Evaluation of the mutagenicity of the S9 fraction that was obtained from rats that were treated with biotin in the Ames test.

\begin{tabular}{|c|c|c|c|c|c|}
\hline \multirow{2}{*}{ Day } & \multirow{2}{*}{ Chemical } & \multirow{2}{*}{ Dose $(\mu \mathrm{g} /$ plate $)$} & \multicolumn{3}{|c|}{ Number of His ${ }^{+}$revertants/plate ${ }^{(\mathrm{a})}$} \\
\hline & & & $\mathrm{B}-{ }^{(\mathrm{b})}$ & $\mathrm{B}+{ }^{(\mathrm{c})}$ & Positive control $^{(\mathrm{d})}$ \\
\hline \multirow[t]{6}{*}{1} & $\mathrm{~B}[\mathrm{a}] \mathrm{P}$ & 0 & $23 \pm 5$ & $18 \pm 1$ & $28 \pm 6$ \\
\hline & & 1 & $55 \pm 17$ & $55 \pm 8$ & $59 \pm 6$ \\
\hline & & 5 & $229 \pm 104$ & $210 \pm 59$ & $433 \pm 143$ \\
\hline & & 10 & $215 \pm 67$ & $220 \pm 61$ & $557 \pm 86$ \\
\hline & & 20 & $304 \pm 49$ & $281 \pm 30$ & $913 \pm 144$ \\
\hline & & Induced revertants $/ \mu \mathrm{g}^{(\mathrm{e})}$ & 40.5 & 52.7 & $62.3^{*}$ \\
\hline \multirow[t]{6}{*}{7} & $\mathrm{~B}[\mathrm{a}] \mathrm{P}$ & 0 & $49 \pm 8$ & $62 \pm 10$ & $66 \pm 7$ \\
\hline & & 1 & $68 \pm 7$ & $66 \pm 8$ & $81 \pm 27$ \\
\hline & & 5 & $132 \pm 7$ & $137 \pm 20$ & $300 \pm 29$ \\
\hline & & 10 & $114 \pm 17$ & $128 \pm 8$ & $436 \pm 99$ \\
\hline & & 20 & $148 \pm 31$ & $159 \pm 15$ & $773 \pm 127$ \\
\hline & & Induced revertants $/ \mu \mathrm{g}^{(\mathrm{e})}$ & 16.5 & 15.0 & $37.4^{*}$ \\
\hline
\end{tabular}

\footnotetext{
(a) The mean number of revertant colonies identified in three replicates in two independent experiments.

(b) The liver $\mathrm{S} 9$ fraction from control rats.

(c) The liver S9 fraction from biotin-treated rats $(2 \mathrm{mg} / \mathrm{kg})$.

${ }^{\text {(d) }}$ The liver $\mathrm{S} 9$ fraction from phenobarbital-treated rats $(60 \mathrm{mg} / \mathrm{kg}) . \beta$-naphthoflavone $(80 \mathrm{mg} / \mathrm{kg})$ was used as a positive control.

(e) The slope at the origin was calculated using the SALANAL software program.

${ }^{*}$ Significantly different from B- and B+ $(P \leq 0.05)$, as assessed using Student's $t$-test.
}

propose that the observed changes to the CYP1A subfamily at the posttranscriptional level may have been directly produced by biotin or derived from a pleiotropic response that was triggered by biotin in the cell and that these changes cause an increase in small regulatory RNAs, such as miRNAs, which silence the subsequent translation of CYP1 mRNA. This hypothesis is currently being tested in experiments that are underway in our laboratory.

In conclusion, biotin administration affected the mRNA expression levels of CYP1A1 and CYP1A2. CYP1 mRNA induction had no effects at the protein or enzyme activity levels, suggesting that posttranscriptional regulation had occurred. The effects of biotin on CYP1A activity were confirmed using several different strategies. These results indicate that biotin does not interfere with CYP1A activity and suggest that biotin administration does not influence CYP1A1- and CYP1A2-mediated drug metabolism.

\section{Conflict of Interests}

The authors declare that they have no conflict of interests.

\section{Acknowledgments}

This study was performed in partial fulfilment of the requirements for the Ph.D. degree in Biomedical Sciences of M. D. Ronquillo-Sánchez (Universidad Nacional Autónoma de México), who was supported by CONACYT fellowship and Fundación Miguel Alemán, A.C. The technical assistance that was provided by Dr. Miguel Tapia is greatly appreciated.

\section{References}

[1] K. Dakshinamurti, "Biotin-a regulator of gene expression," The Journal of Nutritional Biochemistry, vol. 16, no. 7, pp. 419-423, 2005.

[2] J. Zempleni, "Uptake, localization, and noncarboxylase roles of biotin," Annual Review of Nutrition, vol. 25, pp. 175-196, 2005.

[3] R. Rodriguez-Melendez and J. Zempleni, "Regulation of gene expression by biotin (review)," The Journal of Nutritional Biochemistry, vol. 14, no. 12, pp. 680-690, 2003.

[4] S. Wiedmann, J. D. Eudy, and J. Zempleni, "Biotin supplementation increases expression of genes encoding interferon$\gamma$, interleukin-1 $\beta$, and 3-methylcrotonyl-CoA carboxylase, and decreases expression of the gene encoding interleukin- 4 in human peripheral blood mononuclear cells," Journal of Nutrition, vol. 133, no. 3, pp. 716-719, 2003.

[5] S. Wiedmann, R. Rodriguez-Melendez, D. Ortega-Cuellar, and J. Zempleni, "Clusters of biotin-responsive genes in human peripheral blood mononuclear cells," The Journal of Nutritional Biochemistry, vol. 15, no. 7, pp. 433-439, 2004.

[6] C. Fernández-Mejía, "A new panorama for understanding the molecular connections between obesity and type 2 diabetes mellitus," Revista de Investigacion Clinica, vol. 53, no. 3, pp. 209211, 2001.

[7] R. Rodriguez-Melendez, J. B. Griffin, J. Zempleni, and G. Sarath, "High-throughput immunoblotting identifies biotindependent signaling proteins in HepG2 hepatocarcinoma cells," Journal of Nutrition, vol. 135, no. 7, pp. 1659-1666, 2005.

[8] J. Chauhan and K. Dakshinamurti, "Transcriptional regulation of the glucokinase gene by biotin in starved rats," The Journal of Biological Chemistry, vol. 266, no. 16, pp. 10035-10038, 1991.

[9] L. A. de la Vega and R. J. Stockert, "Regulation of the insulin and asialoglycoprotein receptors via cGMP-dependent protein 
kinase," American Journal of Physiology, vol. 279, no. 6, pp. C2037-C2042, 2000.

[10] K. Dakshinamurti and W. Li, “Transcriptional regulation of liver phosphoenolpyruvate carboxykinase by biotin in diabetic rats," Molecular and Cellular Biochemistry, vol. 132, no. 2, pp. 127-132, 1994.

[11] A. Vilches-Flores, A. R. Tovar, A. Marin-Hernandez, A. RojasOchoa, and C. Fernandez-Mejia, "Biotin increases glucokinase expression via soluble guanylate cyclase/protein kinase $\mathrm{G}$, adenosine triphosphate production and autocrine action of insulin in pancreatic rat islets," The Journal of Nutritional Biochemistry, vol. 21, no. 7, pp. 606-612, 2010.

[12] G. Romero-Navarro, G. Cabrera-Valladares, M. S. German et al., "Biotin regulation of pancreatic glucokinase and insulin in primary cultured rat islets and in biotin-deficient rats," Endocrinology, vol. 140, no. 10, pp. 4595-4600, 1999.

[13] Y. Sugita, H. Shirakawa, R. Sugimoto, Y. Furukawa, and M. Komai, "Effect of biotin treatment on hepatic gene expression in streptozotocin-induced diabetic rats," Bioscience, Biotechnology and Biochemistry, vol. 72, no. 5, pp. 1290-1298, 2008.

[14] E. Larrieta, F. Velasco, P. Vital et al., "Pharmacological concentrations of biotin reduce serum triglycerides and the expression of lipogenic genes," European Journal of Pharmacology, vol. 644, no. 1-3, pp. 263-268, 2010.

[15] J. C. Coggeshall, J. P. Heggers, M. C. Robson et al., "Biotin status and plasma glucose in diabetics," Annals of the New York Academy of Sciences, vol. 447, pp. 389-392, 1985.

[16] M. Maebashi, Y. Makino, Y. Furukawa et al., "Therapeutic evaluation of the effect of biotin on hyperglycemia in patients with non-insulin dependent diabetes mellitus," Journal of Clinical Biochemistry and Nutrition, vol. 14, pp. 211-218, 1993.

[17] D. Koutsikos, C. Fourtounas, A. Kapetanaki et al., "Oral glucose tolerance test after high-dose i.v. biotin administration in normoglucemic hemodialysis patients," Renal Failure, vol. 18, no. 1, pp. 131-137, 1996.

[18] O. K. Dokusova and I. V. Krivoruchenko, "The effect of biotin on the level of cholesterol in the blood of patients with atherosclerosis and essential hyperlipidemia," Kardiologiya, vol. 12, no. 12, p. 113, 1972.

[19] C. Revilla-Monsalve, I. Zendejas-Ruiz, S. Islas-Andrade et al., "Biotin supplementation reduces plasma triacylglycerol and VLDL in type 2 diabetic patients and in nondiabetic subjects with hypertriglyceridemia," Biomedicine and Pharmacotherapy, vol. 60, no. 4, pp. 182-185, 2006.

[20] C. Albarracin, B. Fuqua, J. Geohas et al., "Improvement in glycemic control, lipids and insulin sensitivity with the combination of chromium picolinate and biotin in type 2 diabetes mellitus," Diabetes Care, vol. 54, pp. 428-433, 2005.

[21] G. M. Singer and J. Geohas, "The effect of chromium picolinate and biotin supplementation on glycemic control in poorly controlled patients with type 2 diabetes mellitus: a placebocontrolled, double-blinded, randomized trial," Diabetes Technology and Therapeutics, vol. 8, no. 6, pp. 636-643, 2006.

[22] M. Z. Fiume, "Final report on the safety assessment of biotin," International Journal of Toxicology, vol. 20, supplement 4, pp. $1-12,2001$.

[23] S. Hayes, A. Gordon, I. Sadowski, and C. Hayes, "RK bacterial test for independently measuring chemical toxicity and mutagenicity: short-term forward selection assay," Mutation Research, vol. 130, no. 2, pp. 97-106, 1984.
[24] T. H. Ma, M. M. Harris, and V. A. Anderson, "Tradescantiamicronucleus (Trad-MCN) tests on 140 health-related agents," Mutation Research, vol. 138, no. 2-3, pp. 157-167, 1984.

[25] SRI-International, "Microbial mutagenesis testing of substances compound report:F76-041, D-Biotin,” Tech. Rep. PB89-169072, National Technical Information Service, 1979.

[26] R. Rodriguez-Melendez, J. B. Griffin, and J. Zempleni, "Biotin supplementation increases expression of the cytochrome P450 $1 \mathrm{~B} 1$ gene in Jurkat cells, increasing the occurrence of singlestranded DNA breaks," Journal of Nutrition, vol. 134, no. 9, pp. 2222-2228, 2004.

[27] Y. Fujii-Kuriyama and K. Kawajiri, "Molecular mechanisms of the physiological functions of the aryl hydrocarbon (dioxin) receptor, a multifunctional regulator that senses and responds to environmental stimuli," Proceedings of the Japan Academy B, vol. 86, no. 1, pp. 40-53, 2010.

[28] D. W. Nebert, "The Ah locus: genetic differences in toxicity, cancer, mutation, and birth defects," Critical Reviews in Toxicology, vol. 20, no. 3, pp. 153-174, 1989.

[29] S. Rendic, "Summary of information on human CYP enzymes: human P450 metabolism data," Drug Metabolism Reviews, vol. 34, no. 1-2, pp. 83-448, 2002.

[30] D. M. Maron and B. N. Ames, "Revised methods for the Salmonella mutagenicity test," Mutation Research, vol. 113, no. 3-4, pp. 173-215, 1983.

[31] M. M. Bradford, "A rapid and sensitive method for the quantitation of microgram quantities of protein utilizing the principle of protein-dye binding," Analytical Biochemistry, vol. 72, no. 1-2, pp. 248-254, 1976.

[32] K. J. Livak and T. D. Schmittgen, "Analysis of relative gene expression data using real-time quantitative PCR and the 2(Delta Delta C(T)) method," Methods, vol. 25, no. 4, pp. 402-408, 2001.

[33] M. D. Burke, S. Thompson, R. J. Weaver, C. R. Wolf, and R. T. Mayer, "Cytochrome P450 specificities of alkoxyresorufin Odealkylation in human and rat liver," Biochemical Pharmacology, vol. 48, no. 5, pp. 923-936, 1994.

[34] H. Towbin, T. Staehelin, and J. Gordon, "Electrophoretic transfer of proteins from polyacrylamide gels to nitrocellulose sheets: procedure and some applications," Proceedings of the National Academy of Sciences of the United States of America, vol. 76, no. 9, pp. 4350-4354, 1979.

[35] F. P. Guengerich, P. Wang, and N. K. Davidson, "Estimation of isozymes of microsomal cytochrome P-450 in rats, rabbits, and humans using immunochemical staining coupled with sodium dodecyl sulfate-polyacrylamide gel electrophoresis," Biochemistry, vol. 21, no. 7, pp. 1698-1706, 1982.

[36] K. Dakshinamurti, L. Tarrago-Litvak, and H. C. Hong, "Biotin and glucose metabolism," Canadian Journal of Biochemistry, vol. 48, no. 4, pp. 493-500, 1970.

[37] S. F. Zhou, B. Wang, L. P. Yang, and J. P. Liu, "Structure, function, regulation and polymorphism and the clinical significance of human cytochrome P450 1A2," Drug Metabolism Reviews, vol. 42, no. 2, pp. 268-354, 2010.

[38] M. T. Granfors, J. T. Backman, M. Neuvonen, and P. J. Neuvonen, "Ciprofloxacin greatly increases concentrations and hypotensive effect of tizanidine by inhibiting its cytochrome P450 1A2-mediated presystemic metabolism," Clinical Pharmacology and Therapeutics, vol. 76, no. 6, pp. 598-606, 2004.

[39] Z. Hu, X. Yang, P. C. L. Ho et al., "Herb-drug interactions: a literature review," Drugs, vol. 65, no. 9, pp. 1239-1282, 2005. 
[40] B. D. Jeffy, R. B. Chirnomas, and D. F. Romagnolo, "Epigenetics of breast cancer: polycyclic aromatic hydrocarbons as risk factors," Environmental and Molecular Mutagenesis, vol. 39, no. 2-3, pp. 235-244, 2002.

[41] M. Shou, K. W. Krausz, F. J. Gonzalez, and H. V. Gelboin, "Metabolic activation of the potent carcinogen dibenzo[a,l] pyrene by human recombinant cytochromes P450, lung and liver microsomes," Carcinogenesis, vol. 17, no. 11, pp. 2429-2433, 1996.

[42] L. Cancino-Badías, R. E. Reyes, R. Nosti et al., "Modulation of rat liver cytochrome $\mathrm{P} 450$ by protein restriction assessed by biochemical and bacterial mutagenicity methods," Mutagenesis, vol. 18, no. 1, pp. 95-100, 2003.

[43] A. Aguilera-Méndez and C. Fernández-Mejía, “The hypotriglyceridemic effect of biotin supplementation involves increased levels of cGMP and AMPK activation," Biofactors, vol. 38, no. 5, pp. 387-395, 2012.

[44] N. Rodríguez-Fuentes, I. López-Rosas, G. Román-Cisneros, and A. Velázquez-Arellano, "Biotin deficiency affects both synthesis and degradation of pyruvate carboxylase in rat primary hepatocyte cultures," Molecular Genetics and Metabolism, vol. 92, no. 3, pp. 222-228, 2007.

[45] K. Chen and N. Rajewsky, "The evolution of gene regulation by transcription factors and microRNAs," Nature Reviews Genetics, vol. 8, no. 2, pp. 93-103, 2007.

[46] A. Eulalio, I. Behm-Ansmant, and E. Izaurralde, "P bodies: at the crossroads of post-transcriptional pathways," Nature Reviews Molecular Cell Biology, vol. 8, no. 1, pp. 9-22, 2007.

[47] S. P. Chan and F. J. Slack, "microRNA-mediated silencing inside P-bodies," RNA Biology, vol. 3, no. 3, pp. 97-100, 2006.

[48] Y. Z. Pan, W. Gao, and A. M. Yu, "MicroRNAs regulate CYP3A4 expression via direct and indirect targeting," Drug Metabolism and Disposition, vol. 37, no. 10, pp. 2112-2117, 2009.

[49] Y. Tsuchiya, M. Nakajima, S. Takagi, T. Taniya, and T. Yokoi, "MicroRNA regulates the expression of human cytochrome P450 1B1," Cancer Research, vol. 66, no. 18, pp. 9090-9098, 2006.

[50] T. Mohri, M. Nakajima, T. Fukami, M. Takamiya, Y. Aoki, and T. Yokoi, "Human CYP2E1 is regulated by miR-378," Biochemical Pharmacology, vol. 79, no. 7, pp. 1045-1052, 2010. 

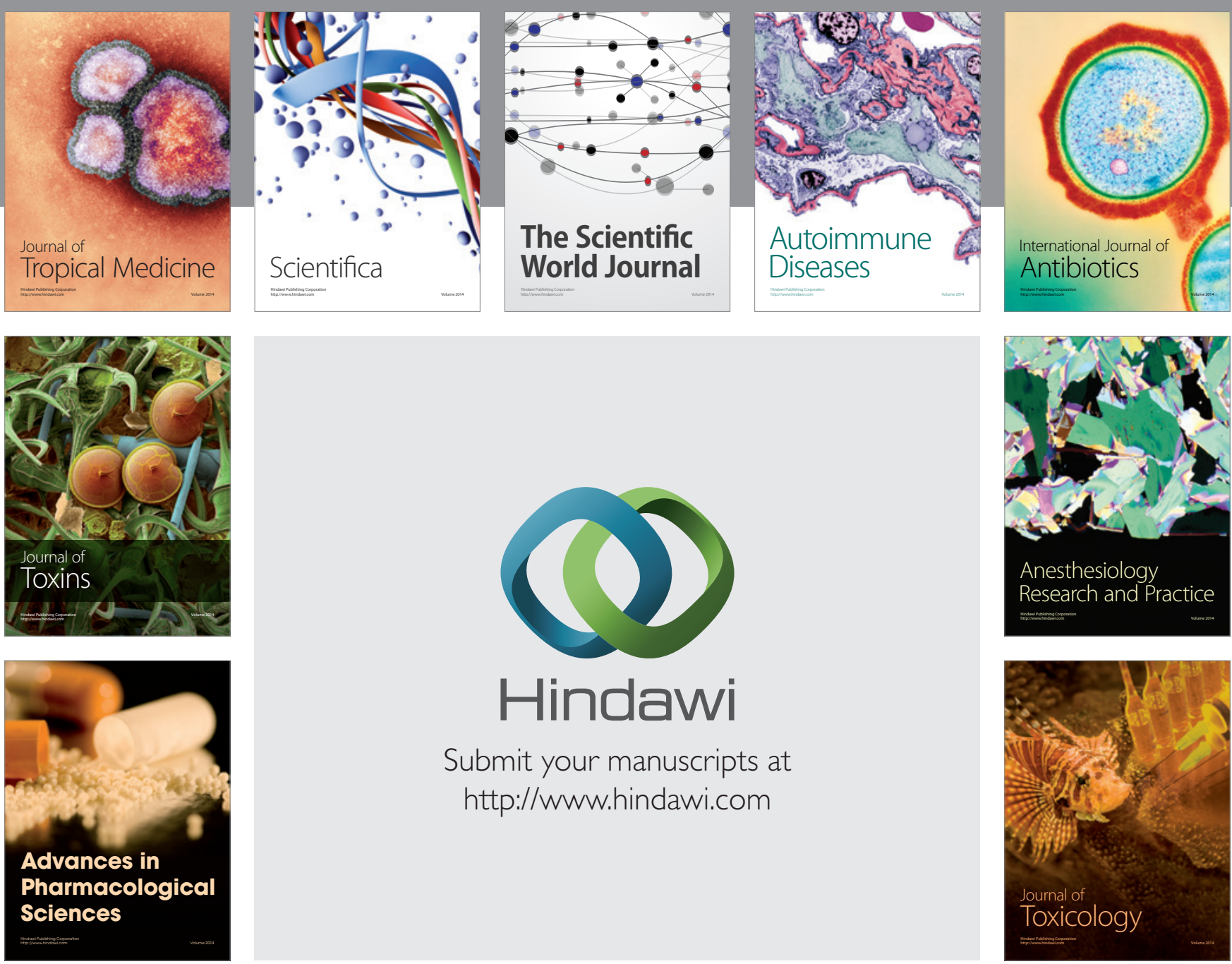

\section{Hindawi}

Submit your manuscripts at

http://www.hindawi.com
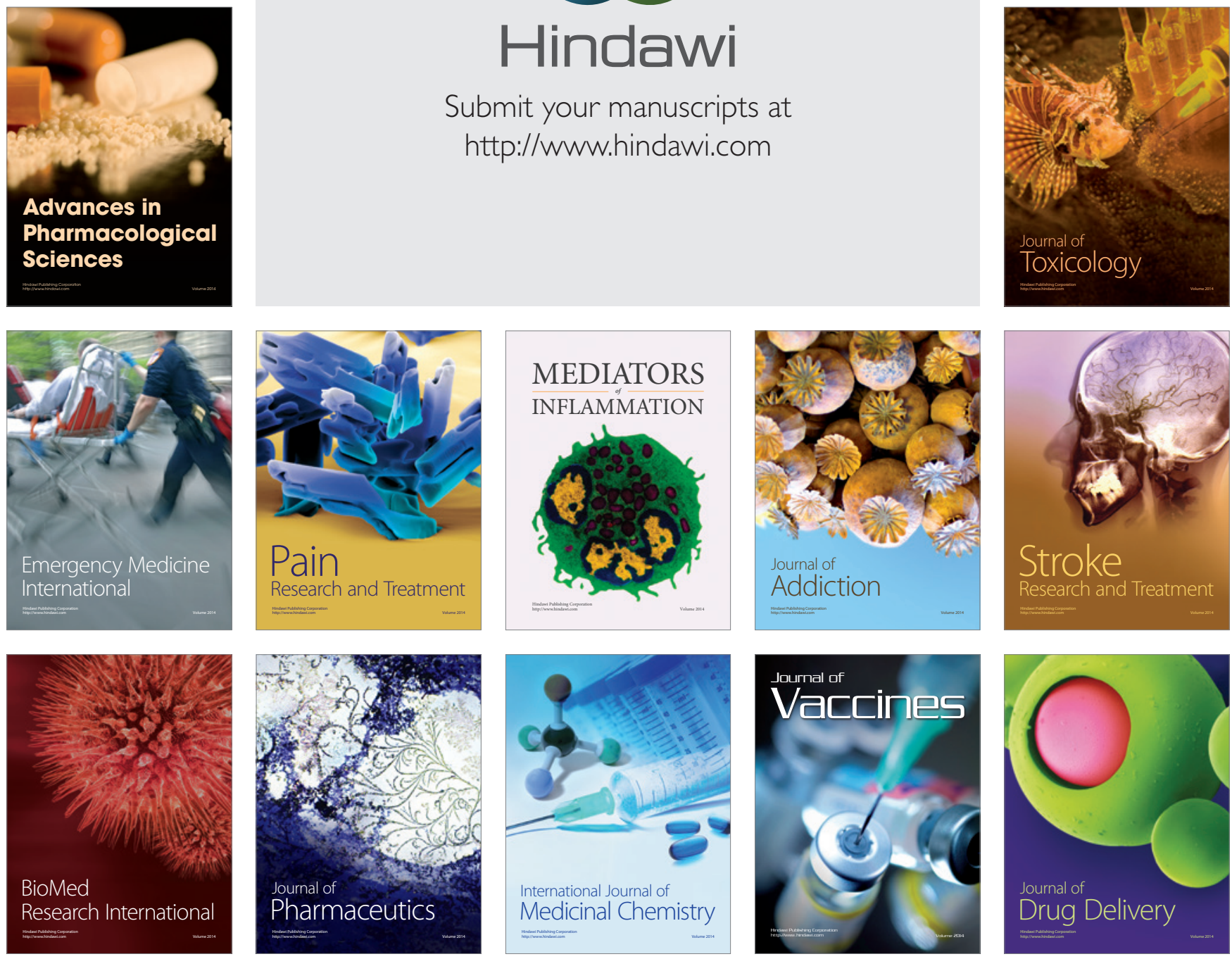